\title{
Health and disease: two philosophical perspectives
}

\author{
LENNART NORDENFELT \\ From the Department of Health and Society, University of Linköping, Linköping, Sweden
}

Is there a philosopher's approach to the concepts of health and disease? Are there any particularly philosophical concepts concerning medical affairs? What point could there be in the existence of such concepts? These questions seem to be well motivated by the title of this paper. What use can a scholarly and humanistic discipline be to a rapidly expanding science such as medicine?

Let us first notice that the relation between medicine and philosophy is not something that has recently emerged. Many of the ancient and mediaeval doctors were also philosophers. The ideas of Plato and Aristotle deeply influenced medical thinking until the 17th century. Many of the most prominent medical theorists of later times, let us just mention Boerhaave, Cullen, and Bernard, had a deep philosophical training and made use of such insights in their theoretical constructions.

It is true, however, that western medicine of the 20th century has lost some of its philosophical background or, more correctly, it has once and for all chosen one philosophical standpoint, viz, extreme empiricism, and then tried to forget that there are any alternatives to it. It has taken its own metaphysics as self evident and then refused to believe that there is any metaphysics left. As a consequence, the means of communication between physicians and philosophers, or between physicians and humanists in general, have become more and more rare and fragile.

But what has been lost and what can philosophy offer? I cannot deal with this question in its generality. Let me instead limit my focus to the initial questions posed in this paper and try to assess what is peculiar to the philosopher's analysis of single medical notions such as health and disease.

I think that there are two fundamental things worth mentioning. On the one hand all philosophers are interested in the formal and logical aspects of these concepts in order, first, to determine their scientific status. This means that the philosopher asks questions such as: Is health a property concept or a relation concept? What kind of logical opposition is there between health and disease? Are they contrary or contradictory concepts? Are health and disease evaluative or descriptive concepts?
On the other hand, a philosopher is also interested in placing the medical notions into a general perspective. He wants to see how they fit in with other concepts and other theories, for instance, to try and see how they form a part of our general picture of man and nature. He believes there can be no philosophy of health without a philosophy of man.

I now wish to illustrate these concerns. My intention is to discuss two concrete philosophical procedures for characterising the notions of health and disease. These procedures have the properties that I have just mentioned. They contain fairly precise reasonings and definitions; they pinpoint formal properties of the concepts characterised; and they also put much emphasis on describing the theoretical contexts or perspectives.

The two perspectives are in a rough form well known to us all. In the first, let us call it the atomistic-biological, perspective man is mainly viewed as a complicated biological organism with a vast number of interacting parts. Accordingly, the central concepts to be used in theory construction are biological, chemical, and, as we shall also see, statistical. In the second, holistic-humanistic, perspective, man is taken to be fundamentally a social agent, a complete human being acting in society. On such a platform the theory construction will primarily use humanistic or social concepts. The concept of a person is central, so are the concepts of action and goal.

Consider now first a modern characterisation of the concepts of health and disease based on an atomisticbiological platform, which has been presented by the American philosopher. ${ }^{12}$ Space forces me to make this presentation brief, and both you and Boorse must excuse me for not taking account of all his sophistications.

The primary notion in Boorse's theory is that of disease or, more precisely, disease entity. A disease entity is concisely defined in the following way: it is the state of an individual which interferes with or even prevents the normal function of some organ or system of organs belonging to the bearer of the state. The key expression here is of course "normal function". What exactly does this mean? 
The normal function of a human organ is, according to Boorse, to be calculated on the species of man as a reference-class. He claims that there is something called the species design for man. This species design is in fact what is described in the biology textbooks. What is described is the typical human being, with typical anatomical, physiological, and chemical features.

But how do we get to know about the species design? According to Boorse, the method is ultimately statistical. But it is not statistical in the following simple sense: he does not claim that the majority of mankind are in all respects in accordance with the species design. No, every organ and every function must be measured separately, and normal values are calculated for each organ. Obviously a result of this can be that very few persons are totally in accordance with the species design for man. This is indeed an intuitively reasonable result. Most of us have some flaw, some local infection, some impairment, etc.

Not all abnormal functions indicate disease, however, in Boorse's biostatistical theory. An organ of an individual may function supernormally, that is, it may be superior to the species design. Such superiority can be identified on the plausible assumption that all functions are related to goals, and these goals can be reached more or less efficiently. Boorse makes such an assumption.

His own words in characterising normal functioning are the following:

"Normal functioning in a member of the referenceclass is the performance by each internal part of all its statistically typical functions with at least statistically typical efficiency, ie, at efficiency levels within or above some chosen central region of their population distribution."2

So much for the basic characterisation of a disease entity. But how do we go from there to understand when a person as a whole is in health or is diseased? Boorse's general answer is simple: A person is in health if he has no disease. He is diseased if he has at least one disease.

Being diseased is, however, not tantamount to being troubled by one's disease, that is, being ill. By introducing the concept of illness Boorse makes a slight concession to the holistic perspective on health. In more precise words, he defines illness in the following way:

"A person is ill if he has a disease which is serious enough to be incapacitating and therefore is (i) undesirable to its bearer, (ii) a title to special treatment, and (iii) a valid excuse for normally criticisable behaviour."

Let us now note some features in Boorse's conceptual machinery. (i) The primary notion in his chain of definitions is the one of disease entity. Being diseased, being in health, and being ill are derivative notions.

(ii) Health is defined negatively as the absence of disease.

(iii) Health and disease are characterised as purely descriptive, scientific notions. There is no evaluative component.

An exception to this is the concept of illness, which is explicitly evaluative and serves as some kind of bridge between the scientific notions and the everyday notion of being ill.

Before giving further comments on the biostatistical theory, let us now turn to its counterpart, a modern variant of a holistic-humanistic perspective. The theory to be discussed is quite clearly presented by the American philosopher ${ }^{3}$ as well as by the Finnish philosopher. ${ }^{4}$ Following the latter, I shall call it the equilibrium theory. (Observe, however, that equilibrium is here not taken in the sense of biological homeostasis.)

The primary concept to be characterised in the equilibrium theory is health. The theory starts off by characterising the general conditions that must obtain for an individual (as a whole) to be healthy. The basic answer is simple. A person is in health if his capabilities are adequate relative to his goals; a person is ill or in unhealth if this is not the case. He is only slightly ill if his capabilities are almost adequate; he is gravely ill if they are quite inadequate.

Observe that the conceptual context here is humanistic or social. The basic concepts are such things as action, capability, and goal. On the equilibrium theory, both health and unhealth (which is taken to be equal to illness) can be completely characterised in such terms.

But what about disease? Does the equilibrium theory offer a non-biological characterisation of a disease entity? No, the equilibrium theory must in its turn provide a bridge between the humanistic concepts and the scientific biological ones. This is done in the following way. Diseases affect the basis of a person's capabilities. They are states of an anatomical, physiological, or psychological kind, such as tend to restrict people's capabilities relative to their goals.

Observe a number of things here. Although diseases certainly are characterised in biological (as well as psychological) terms, they are not completely so characterised. In contrast with Boorse, there is no talk about statistical abnormality. Such facts do not, according to the equilibrium theory, affect something's status as a disease. What is important is whether the state in question tends to prevent people's capabilities to act. Cancer is not a disease because it is an abnormal state; it is a disease because it tends to entail grave incapacity. 
The use of the weak expression "tend to restrict capabilities" is intentional. Not all diseases are in individual cases incapacitating. This is the truth that Boorse expressed by saying that not all diseases are illnesses.

Let us now summarise some features of the equilibrium theory.

(i) The primary notion in the chain of definitions is health. Unhealth or illness as well as disease are derivative notions.

(ii) Health is defined positively as the equilibrium between capabilities and goals.

(iii) Health and disease are highly evaluative notions and do not just contain a scientific, descriptive element.

So much for a presentation of the two theories. How should we evaluate them? Is there a rational procedure by which we can select one theory in preference to the other?

It would take us too far if we were to discuss the theory of conceptual analysis here. Let me just say that a fundamental criterion of a successful conceptual analysis is that it captures our ordinary intuitions, such as they are expressed in ordinary language. A reasonable theory of health and disease must have the power to explain our everyday discourse about these matters (or at least most aspects of our everyday discourse).

Can one say that either of the two theories is superior to the other in this respect? Let me first state that both entail problems. It is not difficult to find counterintuitive cases resulting from both. I believe, however, that there is a difference in kind between these problems. I think that the difficulties of the equilibrium theory can be avoided by making minor changes, thus keeping the main platform intact. It is more difficult to see how the biostatistical theory could be amended without changing the whole platform of the theory.

The fundamental question is whether statistical abnormality (or subnormality) of some organic function really has anything to do with ascription of disease status. Consider the following conspicuous examples: a trained athlete often has a subnormal pulse; there are pulse rates below 40 beats per minute. The heart function of an athlete is then in this respect subnormal. Given a biostatistical theory, the athlete should on these grounds alone be considered diseased. An Indian yogi can transcend a great number of physiological and biochemical standard limits. His pulse rate can be very low; his respiration can reach an extremely low level and it can even cease to function during some period of time. Again, the yogi would be considered diseased on a biostatistical conception.

In both cases our normal intuitions run contrary to these conclusions. The bearers of the above mentioned subnormal values are extremely strong and healthy persons. What has gone wrong?

The biostatistical theory has not taken into account the phenomenon of compensatory mechanisms. Low efficiency of one function may be compensated for by high efficiency of some other function. Quite often the combined result of these functions in an individual is considered to be healthy or to indicate health. The heart rate of an athlete is compensated for by the strength of the heart beat. The general physiological and psychological control that the yogi possesses compensates for temporary low efficiency on the part of some of his organs.

Can one then not take into account this phenomenon in a revised version of the biostatistical theory? Can one, for instance, not define the notion of function in such a way as to solve the problem? I have tried elsewhere to show that it is very difficult to do so. And if one tries very hard there is a great risk that the resulting theory will be much more like the equilibrium theory than the initial biostatistical theory. ${ }^{5}$

What then are the problems with the equilibrium theory? There are certainly great problems of interpretation. The notion of goal, in particular, has to be developed in more detail. Should we, for instance, take into account any old wants and wishes that a person may have in calculating his health? Obviously not, that will give absurd results. We can only consider such wants of his as he is actually prepared to act upon, wants that have resulted in real decisions.

Consider a further difficulty with the equilibrium conception. It has to do with the person who has extremely low ambitions, with goals set at a very low level. He is in a position in which he can hardly become unhealthy given the equilibrium theory. He can have many diseases, he can become quite disabled from an intuitive point of view without that affecting his health. If his goals are minimal enough he will still remain in equilibrium.

I think that this last observation is the most serious, and it has convinced me that the individual's own goal cannot be the sole factor relative to which his capabilities should be settled. A person must possess a minimal amount of vitality, including a minimal set of goals or ambitions, before we can label him healthy. One of the most important tasks for a philosopher of health is to try to characterise this minimum. Space now prevents me from discussing any such attempts.

Let me instead summarise what I take to be the convincing ideas in the equilibrium theory. I think that there is a deep truth in the view that health is fundamentally connected with the concept of ability and that unhealth or disease is, likewise, connected with the concept of disability. The healthy man is an able man, and the unhealthy one is disabled. Moreover, ability must be judged relative to goals. The 
disabled person is the one who cannot reach a certain set of goals. The equilibrium theory has suggested what these goals are. We cannot entirely agree. But perhaps the most adequate alternative strategy is not to search for another particular set of goals. Perhaps it is more plausible to assume that the terms "health" and "disease" are ambiguous in this respect. Different discourses may indicate different sets of goals. The physician may operate with one set; the insurance lawyer with another; most laymen with a third, etc. The existence of such differences does not invalidate our previous analysis. It only indicates that it must be pursued much further.

\section{References}

${ }^{1}$ Boorse $\mathrm{C}$. On the distinction between disease and illness, Philosophy \& Public Affairs 1975; 5: 61.

2 Boorse C. Health as a theoretical concept, Philosophy of Science 1977; XLVI: 559.

${ }^{3}$ Whitbeck C. A theory of health. In: Caplan AL, Engelhardt HT jr, McCartney JJ, eds. Concepts of health and disease. Reading, Massachussetts: Addison \& Wesley Publishing Company, 1981.

${ }^{4}$ Pörn I. An equilibrium model of health. In: Nordenfelt L, Lindahl I, eds. Health, disease, and casual explanations in medicine. Dordrecht: Reidel Publishing Company, 1984.

${ }^{5}$ Nordenfelt L. On the nature of health. Dordrecht: Reidel Publishing Company, in press. 